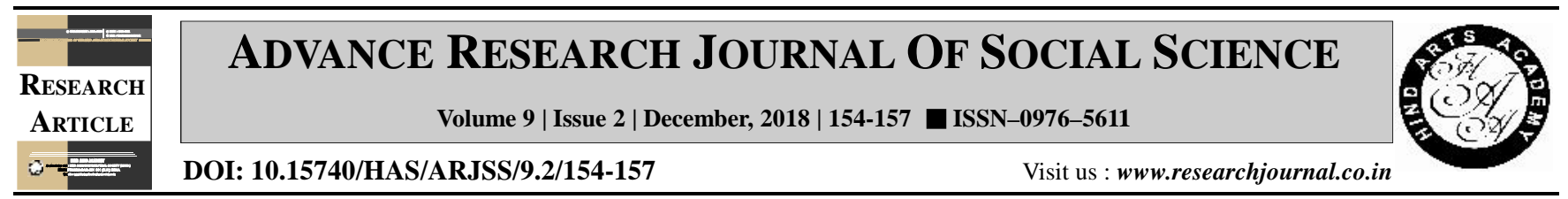

\title{
A study on moral judgement ability of school students
}

Poppy Gogoi ${ }^{1 *}$, Tulika Borah ${ }^{1}$ and Borsha Neog ${ }^{2}$

${ }^{1}$ Department of Human Development and Family Studies, College of Community Science, Assam Agricultural University, Jorhat (Assam) India

${ }^{2}$ Department of Agricultural Statistics, College of Agriculture, Assam Agricultural University, Jorhat (Assam) India

(Email : poppygogoi94@gmail.com; tulikabaruah@gmail.com; borshaneog@aau.ac.in)

\section{ARTICLE INFO :}

Received : 12.06 .2018

Revised : 03.11 .2018

Accepted : $\quad 07.11 .2018$

\section{KEY WORDS :}

Moral development, Moral judgement ability

\section{HOW TO CITE THIS ARTICLE :}

Gogoi, Poppy, Borah, Tulika and Neog, Borsha (2018). A study on moral judgement ability of school students. $A d v$. Res. J. Soc. Sci., 9 (2) : 154-157, DOI: 10.15740/HAS/ARJSS/9.2/154-157. Copyright@2018 : Hind Agri Horticultural Society

*Author for correspondence

\begin{abstract}
Moral development is an important aspect in human life along with physical, social, cognitive and emotional development. Many research studies have indicated that home and school environment, involvement in social activities, parental involvement and education etc. has a great impact on children's moral development. The present study is an attempt to study the moral judgement ability of school students and to find out if there is any gender difference in moral judgement ability. The sample consisted of 100 students, out of which 50 were girls and 50 were boys. The moral judgement was measured by using Moral Judgement Test developed by Verma and Sinha (1971). Result revealed that there is average and above average moral judgement ability among school students but girls have high moral judgement ability than boys which is significant at 0.05 significant level.
\end{abstract}

